\title{
CARTA PARA INFÂNCIA: DEVIR CRIANÇA EM DEVANEIOS POÉTICOS
}

\author{
Dulce Mari da Silva Vossi \\ Viviane Castro Camozzato ${ }^{\text {ii }}$ \\ Semíramis Martins Corrêaiii
}

\begin{abstract}
Resumo: Esta escrita apresenta maquinações do pensamento acerca de experiências vividas no Curso de Extensão Infâncias: territórios de escutas e diálogos, que envolveu educadoras das escolas de Educação Infantil, da cidade de Bagé/RS, em escritas de si de memórias das infâncias. Produção de memórias não como retorno ao passado perdido, mas como ação criadora de afecções sensíveis que inventam devir criança em relações íntimas com as coisas, seres, tempos e lugares imaginados, lembrados, e que podem multiplicar potências transformadoras das nossas presenças no mundo num movimento de provocação a criação de docências outras.
\end{abstract}

Palavras-chave: Formação docente; Memórias; Devires criança.

\section{CHILD LETTER: TO DEVE A CHILD IN POETIC DEVANISHES}

\begin{abstract}
This writing presents machinations of thought about experiences lived in the Extension Course "Childhoods: territories of listening and dialogues" that involved educators from early childhood education schools, in the city of Bagé/RS, in writings about childhood memories. Production of memories, not as a return to the lost past, but as a creative action of sensitive affections that invent to come to a child in intimate relationships with things, beings, imagined times and places, remembered, and that can multiply transformative powers of our presence in the world in a movement of provocation and the creation of other teaching.
\end{abstract}

Keywords: Teacher training; Memories; Devires child.

\section{Por onde andamos ao andar dos sonhos}

Compartilhamos aqui maquinações do pensamento em torno de experimentações acontecidas no Curso de Extensão Infâncias: territórios de escutas e diálogos, que reuniu um grupo de trinta e cinco participantes, incluindo educadoras e supervisoras das redes públicas de ensino que atuam nas escolas de Educação Infantil, discentes de Cursos de Pedagogia e Assistência Social, além das seis formadoras e das duas coordenadoras dos Grupos de Pesquisa que promoveram esta ação: Deslogogias da Universidade Estadual do Rio Grande do Sul (UERGS) e Philos Sophias da Universidade Federal do Pampa (UNIPAMPA), ambos vinculados às unidades acadêmicas situadas na cidade de Bagé, Rio Grande do Sul, Brasil. 
Maquinações do pensamento inspiradas em conceitos da filosofia da diferença de Deleuze e Guattari (2012a; 2012b) e de estudos acerca da ética, artes de si mesmo, estética da existência e escrita de si, presentes na última fase da vasta produção de Michel Foucault (2004), quando escreve sobre estética da existência, indo à Antiguidade clássica grega e romana a partir de algumas expressões, tais como: "retornar a si”, "exercício de si sobre si”, "voltar a si mesmo", entre outras, associadas a um cuidado de si grego, uma série de ações para cuidar de si mesmo, fazer da vida uma obra de arte. Acerca disso, Deleuze (1992) esclarece que o retorno aos gregos, feito por Foucault, permite indagar o presente e as condições de constituição das subjetividades.

Nesse sentido, nosso objetivo neste texto é trazer à tona os agenciamentos e afecções experimentadas no curso que nos permitiram indagar as condições de produção da docência na Educação Infantil e multiplicar potências nos modos de pensar e fazer nosso querer artista como educadoras de crianças pequenas, deslocando e abrindo brechas para a criação de devires. Entendemos que escrever uma carta para a infância poderia mover potências para pensarmos as práticas de escolarização e a docência de modo a desviá-la das práticas da vida cotidiana que implicam em uma negação das diferentes infâncias. Por um lado, sabemos o quanto a experiência - enquanto possibilidade para a transformação, o diferimento - tem sido rara em nossos tempos. Por isso, apostamos na afirmação da singularização das infâncias que acontece de diferentes modos ao experimentá-las.

\section{O apanhador de sonhos}

Consideramos que o Curso de Extensão Infâncias: territórios de escutas e diálogos propiciou o contato e a produção de agenciamentos e afecções entre educadoras da Educação Infantil e pesquisadoras das infâncias, que coabitaram territórios potencializadores de deslocamentos do pensamento em torno da singularização das existências.

Não há um único modo de existir, de ser o que se diz ser, não há a forma-homem universal, o que há é um movimento de dissolução das formas criadas, multiplicidades de multiplicidades (DELEUZE; GUATTARI, 2012b). Trata-se de compreender que existências são forjadas nas relações estabelecidas entre seres humanos e não-humanos, elementos artificiais e naturais, ou seja, o plano real e individual não se constitui de modo fixo, mas é gerado como máquina abstrata que não cabe numa forma ou figura absoluta e universal, e sim recorta, por velocidades e lentidões, as dimensões do real que individua. Assim, configuramRevista Interinstitucional Artes de Educar. Rio de Janeiro, V. 7, N. 1 - pág. 102-115 janeiroabril de 2021: "Pedagogias Vitais: Corpo, Desejo e Educação" DOI: 10.12957/riae.2021.54864 


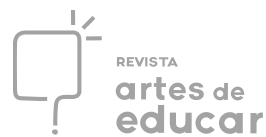

se diferentes planos de imanência, diferentes composições que correspondem a certos graus de intensidade que cada indivíduo experimenta, aumentando ou diminuindo sua potência de agir. Composições de afetos que são devires.

Portanto, é em termos de heterogêneos, de co-funcionamento e contágio entre coisas, seres e forças, irredutíveis a isso ou aquilo, irredutíveis a unidades ou ao plano de organização, que se deve partir do que se tem, do que se diz ser, para extrair dessas formas o que se deseja e se desconhece, o que se pode tornar, acontecimentos em que entram em jogo agenciamentos de um corpo máquina, ou seja, um corpo potência (DELEUZE; GUATTARI, 2012b).

Logo, devir criança nada tem a ver com voltar a um tempo, uma fase cronológica da vida humana chamada infância. Devir criança não é uma questão de correspondência, de retornar a um tempo passado ao distanciar-se do "real", entendido como o atual (o visível das formas e o invisível das sensações), e viver o "imaginário" que é a potência do falso que serviria para discernir verdadeiro e falso na realidade. Devir criança é movimento que transcende a dualidade adulto/criança. Entrar na zona de vizinhança entre um corpo adulto e um corpo criança e dissolver as formas ao experimentar um plano de imanência de outras vidas possíveis. Movimento que acontece diferentemente em cada processo de individuação, de dessubjetivação do sujeito-corpo unidade. Sendo que, a individuação de cada vida não é a mesma coisa que a individuação do sujeito que a leva ou suporta, mesmo que os tempos pareçam iguais, pois jamais se efetiva na temporalidade das formas ou substâncias medidas, determinadas e fixadas em etapas cronológicas. O tempo medido cronologicamente, tempo khrónos, é atravessado por um outro tempo indefinido de composição de hecceidades, o tempo aion, das velocidades e intensidades com que as individuações acontecem (DELEUZE; GUATTARI, 2012b).

Ao produzir memórias das infâncias nos remetemos, num primeiro plano (plano de consistência), a uma condição de existência presa ao passado. Contudo, o movimento do pensamento e da imaginação aí posto em ação provoca o deslocamento entre dois pontos passado e presente; adulto e criança - como força de composição de um devir criança, em decomposição simultânea do dualismo, num plano de imanência, pois devir é coexistência de durações em que se mesclam coisas, seres, ambientes, sensações, atos, emoções, tempos, espaços numa ordem de aliança: “[...] é no vasto domínio das simbioses que coloca em jogo seres de escalas e reinos inteiramente diferentes, sem qualquer filiação possível. Há um bloco de devir que toma a vespa e a orquídea, mas do qual nenhuma vespa-orquídea pode descender" (DELEUZE; GUATTARI, 2012b, p. 96). 
Neste movimento, o devir criança acontece como componente minoritário que pode mover o adulto da sua condição molar, majoritária, e desterritorializar tal condição num processo de involução criadora, já que:

Em todas as crianças, como se, independentemente da evolução que a puxa em direção ao adulto, haveria na criança lugar para outros devires, "outras possibilidades contemporâneas", que não são regressões, mas involuções criadoras, e que testemunham "uma inumanidade vivida imediatamente no corpo enquanto tal", núpcias anti-natureza "fora do corpo programado" (DELEUZE; GUATTARI, 2012b, p. 68, grifos das autoras).

Tratamos, aqui, destes movimentos de afetar e ser afetado, de ter experiências com o tecido sensível, porque tais experiências são desalojadoras e ampliam o campo do possível. Estávamos envolvidas, no curso de extensão referido, com professoras interessadas em infâncias e educação infantil. Éramos, ao mesmo tempo, movidas pelo desejo de pensar uma formação outra - sobretudo porque cingida, aberta, não classificável. Queríamos afetar e sermos afetadas. Daí pensamos que a experiência das cartas nos permitiria o deslocamento das formas e do tempo que circunscrevem a infância como fator biológico e cronológico e o exercício da docência como condução a uma outra etapa da vida delimitada pela lógica moderna, onde a criança precisa educar-se para fazer parte do mundo em que vive. Docência que se constitui numa verdade sobre a infância enquanto etapa de desenvolvimento evolutivo e uniforme que quantificam, classificam e padronizam os diferentes modos de "ser criança". Normalização da infância que acaba por "determinar os níveis, fixar as especialidades e tornar úteis as diferenças, ajustando-as umas às outras" (FOUCAULT, 1999, p. 154).

Padronização das infâncias que transforma em unidade do mesmo os diferentes modos pelos quais crianças experimentam suas existências, criam os modos de inventar infâncias, atravessados pelas condições sociais de cada território que habitam, muitos destes, desprovidos do que se concebe como infância ideal. Larrosa (2017, p. 230) nos diz que " $a$ infância é algo que nossos saberes, nossas práticas e nossas instituições já capturaram". O que nos leva à educação das crianças pautada num "modelo ideal" do que é ser criança ou de como esse período da infância deve ser vivido. Ao propor esse ideal estamos negando diferentes modos de viver e se constituir criança.

Discursos que governam uma infância formatada como modelo em nome de protegê-la e conduzi-la à vida adulta, afastando as crianças dos perigos que a cercam: "[...] um tipo de infância inventada como marginal, perigosa, contudo, aquela que mesmo sem o adulto para protegê-la e ampará-la, produz um cotidiano que possibilite sua sobrevivência e a eles se 


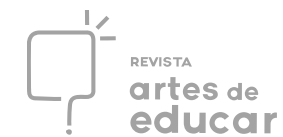

deixa viver" (DORNELLES, 2010, p. 07). Embora as instituições, como a escola, persistam em desejar governar as infâncias e docências, as múltiplas infâncias acontecem e, por muitas vezes, escapam às "capturas" universalizantes, às práticas de governo das subjetividades.

Por meio da proposição das escritas de si em cartas para as infâncias procuramos disparar movimentos de desterritorialização dos corpos programados para viverem a condição majoritária de educadoras adultas e experimentar a involução criadora de devires criança. Uma espécie de olhar para si, se perceber, trabalhar sobre si mesmo, colocar sob suspeita as práticas de escolarização das infâncias que impedem ou inibem as possibilidades de existência criadora das crianças e das relações que elas estabelecem entre si e com os ambientes em que vivem. Pensamos ser este um dos desafios cruciais para outras docências possíveis.

Ora, de que modo investir na potência afirmativa das infâncias senão pela passagem, em si, de uma afetação da infância? De um reconhecimento, em suma, da infância como uma força que estilhaça certezas, prescrições e abre o campo das possibilidades? Por isso, no curso, não trabalhamos com prescrições, formatos fechados, mas com experiências, pois: "Quando a infância é amiga da experiência, longe de ser uma fase a ser superada, ela se torna uma situação a ser estabelecida, atendida, alimentada, sem importar a idade da experiência" (KOHAN, 2005, p. 244-245).

Afinal, se: "Nossos tempos são hostis a uma infância afirmativa, resistente, duradoura", também "podemos pensar em outra experiência, a máscara de sonhos incômodos, imprescindíveis embora irrealizáveis" e "que enfrenta sua outra máscara, a combate, a resiste, a hostiliza; uma experiência amiga da infância" (KOHAN, 2005, p. 240).

Isso nos parece um gesto caro à docência: afirmar um encontro com as infâncias que permita - com e a partir delas - a abertura ao inesperado, ao impensado, à descontinuidade e à pluralidade. Nada de oposição nem de comparação, mas de afirmação e composição.

\section{O sonhar das coisas e as coisas sonhadas}

No Curso de Extensão Infâncias: territórios de escutas e diálogos, investimos na escuta e no diálogo acerca da docência na Educação Infantil com crianças pequenas em experimentações de afecções sensíveis ao produzir memórias de infâncias e, com elas, criamos relações íntimas com as coisas, seres, tempos e lugares imaginados, forças que potencializaram devires criança. 


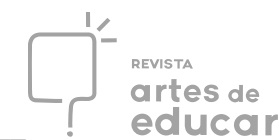

A experiência da escrita das cartas para as infâncias aconteceu numa tarde ensolarada de temperatura amena no primeiro dia de primavera. $\mathrm{O}$ território foi criado e habitado no gramado num cantinho perto do portão de entrada da UERGS, à sombra das folhagens das árvores que dançavam a cada leve rajada de vento. Sentamos em almofadas e tapetes espalhados aleatoriamente. Cada uma foi se acomodando de forma tímida, sentar no chão, dividir o tapete com quem não conhecia, "onde está a minha almofada", "para onde vou", “tem vento, tem folha, vai voar”. Pareciam crianças pegas de surpresa!

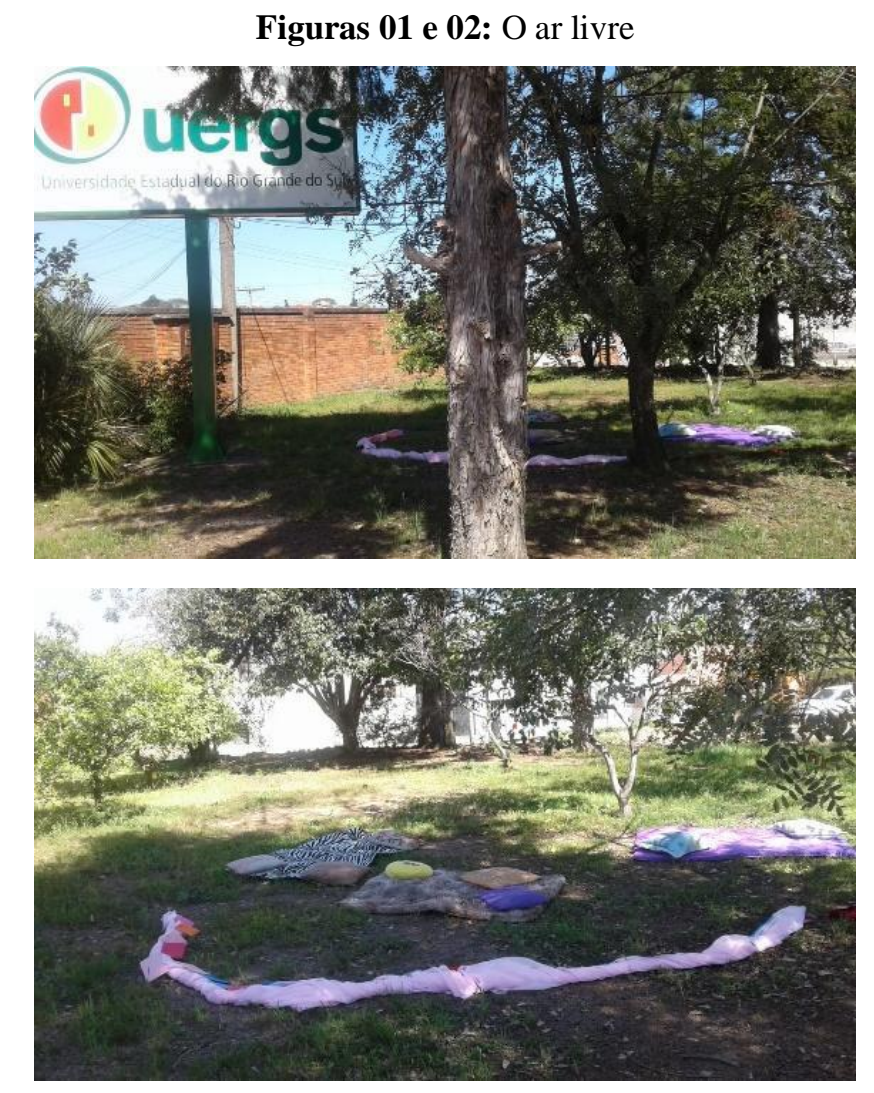

Fonte: arquivo digital das autoras

Por que escolhemos esse lugar quase sempre silencioso no dia a dia das pessoas que circulam por ali? Que encontros poderiam acontecer nesse ambiente? As respostas, se é que elas existem, surgem ao longo dos acontecimentos aqui narrados.

$\mathrm{O}$ pátio remete ao liberto, às infâncias vividas por muitas de nós que habitamos cidades do interior do estado do Rio Grande do Sul (RS). Estar ao ar livre, explorar diferentes espaços, desacomodar corpos, criar novas relações com outros/as tantas.

As cartas foram iniciadas com frases como: "Olá infância! Quantas saudades de você"; "Vinte e duas primaveras depois escrevo para ti esta carta"; "Infância, coisa boa 


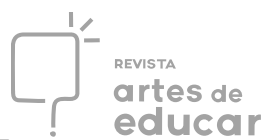

conversar contigo"; "Minha querida infância, a saudade de ti me causa suspiros... como gostaria de reencontrar você...”.

Figuras 03 e 04: $\mathrm{O}$ escrever
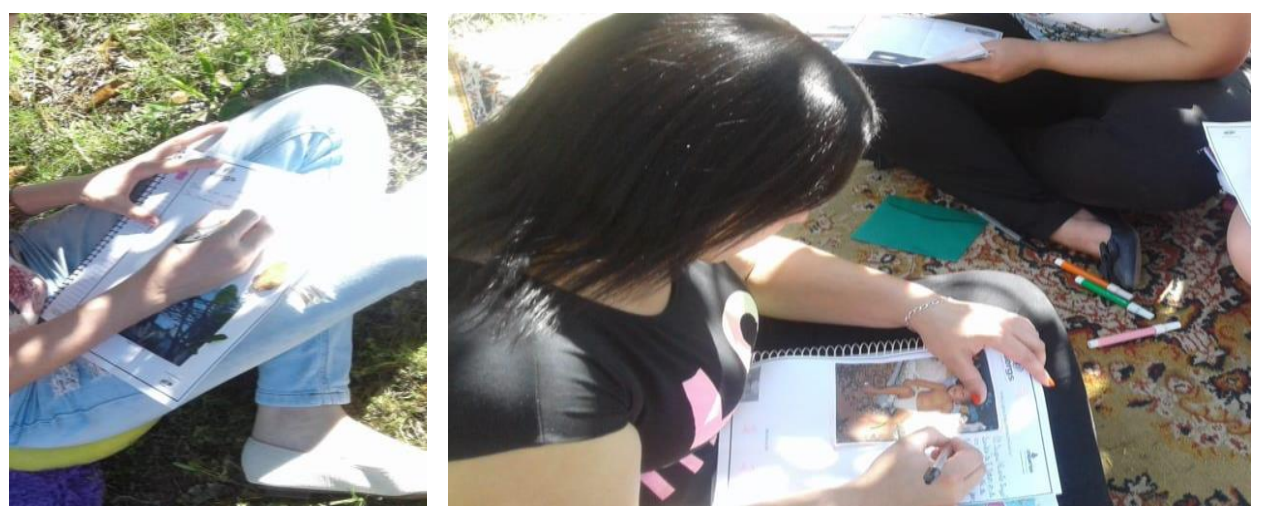

Fonte: arquivo digital das autoras

A escrita de si nas cartas possibilitou a experimentação de múltiplos deslocamentos em relação ao tempo vivido, sentindo cheiros, sons e sabores: "[...] sinto o cheiro das flores $e$ árvores, posso escutar o canto do galo e o latido dos cães correndo ovelha". Escritas que expõem um "estar lá" estando aqui, no presente.

\section{Imagem 05 e 06: As cartas}
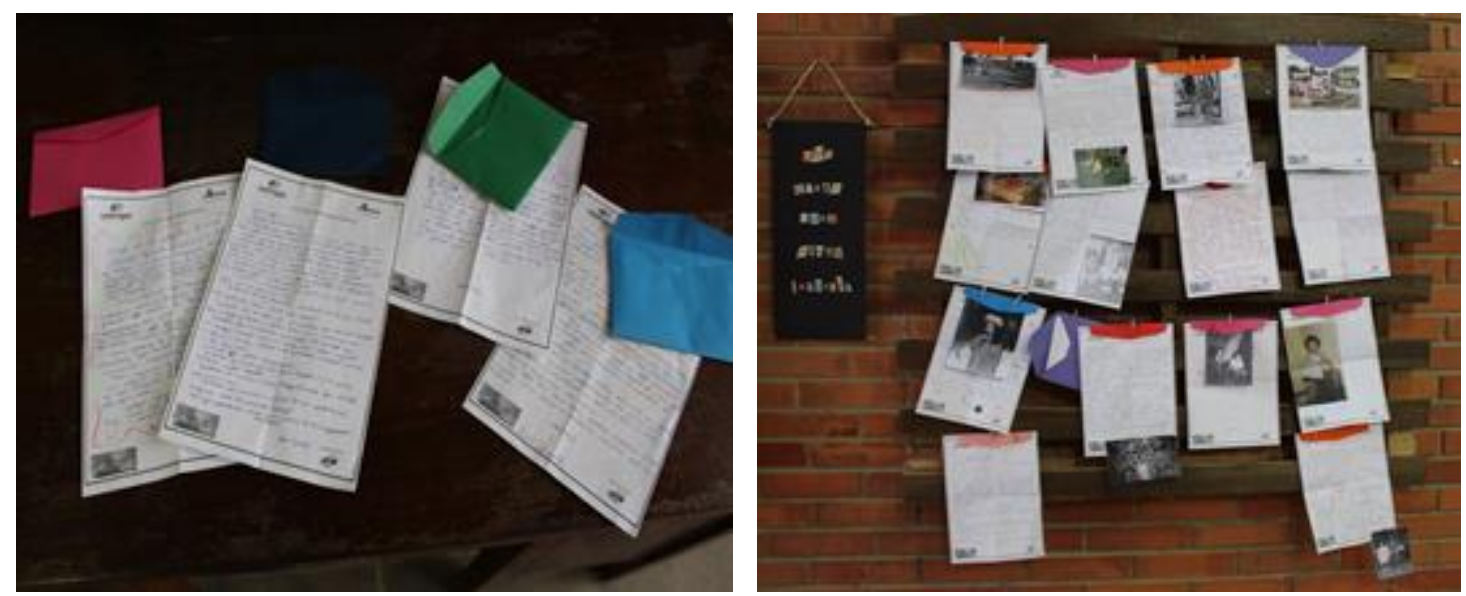

Fonte: arquivo digital das autoras

Como destacado anteriormente, se a infância é uma condição, uma forma de subjetividade que escapa às determinações etárias, abrir o campo da experiência é um modo de ativar um encontro com a infância. Algo que dá sentido há uma (ex)posição necessária, porque articulada à criação de posições de sujeito de professoras que possam, sobretudo, viver 
a temporalidade da experiência consigo e com crianças pequenas. Dos movimentos, sensações, ditos e não ditos, começava-se um primeiro deslocamento, a possibilidade de uma nova experiência. Como nos diz Larrosa (2017, p. 25), a experiência:

[...] requer um gesto de interrupção, um gesto que é quase impossível nos tempos que correm: requer parar para pensar, parar para olhar, parar para escutar, pensar mais devagar, olhar mais devagar, e escutar mais devagar. Um movimento de sutil delicadeza [...] abrir os olhos e os ouvidos, falar sobre o que nos acontece, aprender a lentidão, escutar os outros, cultivar a arte do encontro, calar muito, ter paciência e dar-se tempo e espaço.

Em todas as cartas, a infância está associada ao brincar livremente e em interação que acontece entre crianças, com as coisas e lugares habitados: "jogar bola", "andar de bicicleta", "esconder", "pega-pega", "subir nas árvores", "fazer comidinha", "fazer roupinha para as bonecas", "brincar na rua com os amigos", "brincar junto", "brincar com os primos", "brincar com a gata no pátio".

Deliciosos devaneios: "Ficávamos uma manhã inteira correndo até a vovó chamar para o almoço e que rico almoço, aquele feijão feito em panela de ferro e no fogão a lenha que ela faz até hoje. Que delícia!!!!”. "Sentir gosto de tutti-fruti na boca, cheiro de arroz de leite fresquinho".

Devaneios que, nas palavras das cursistas, nos fizeram experimentar um tempo atemporal, um não-lugar entre o presente o passado: “[...] saudosas lembranças daquele tempo bom... tempo de não sentir passar o tempo"; "Um conselho para você, vá lá, seja criança, e mesmo depois que crescer, ainda seja criança e nunca perca esse brilho nos olhos que carregas".

As crianças que fomos permanecem em nós e imaginá-las é reencontrá-las numa existência sem limites em que podemos alçar voos poéticos de intensa beleza: "Como não falar de beleza psicológica diante de um acontecimento sedutor da nossa vida íntima? Essa beleza está em nós, no fundo de nossa memória. Ela é a beleza de um impulso que nos reanima, que põe em nós o dinamismo de uma beleza de vida" (BACHELARD, 1988, p. 95).

Diz ainda que: "Uma infância potencial habita em nós. Quando vamos reencontrá-la nos nossos devaneios, mais ainda que na sua realidade, nós a revivemos em suas possibilidades". É assim que, "[...] sonhamos no limite da história e da lenda. Para atingir as lembranças de nossas solidões, idealizamos os mundos em que fomos criança solitária [...] Essa infância, aliás, permanece como uma simpatia de abertura para a vida" (Idem, 1988, p. 96). 
Por isso, pensamos que, com as cartas, foi possível experimentar um movimento de repetição que excede a rememoração, já que os diferentes modos pelos quais imaginamos as lembranças das infâncias, tornaram-se criação de devires criança, movidos por fantasias, sensações, emoções num tempo/espaço que desterritorializou passado e presente, existências outras em meio à uma vida adulta e infantil.

O passado rememorado não é simplesmente um passado da percepção. Já num devaneio, uma vez que nos lembramos, o passado é designado como valor de imagem. A imaginação matiza desde a origem os quadros que gostará de rever. Para ir aos arquivos da memória, importa reencontrar, para além dos fatos, valores. Não se analisa a familiaridade contando repetições. As técnicas da psicologia experimental mal conseguem examinar um estudo da imaginação considerada em seus valores criativos. Para reviver os valores do passado, é preciso sonhar, aceitar essa grande dilatação psíquica que é o devaneio, na paz de um grande repouso. Então a Memória e a Imaginação rivalizam para nos devolver as imagens que se ligam à nossa vida. (BACHELARD, 1988, p. 99)

Cada um/a, a sua maneira, na solidão da escrita de si, inventou imagens de infâncias e, ao dialogar com as outros/as que ali estavam, fez da repetição uma potência própria da linguagem e do pensamento, uma obra de singularização da existência em vibrações, giros, danças, saltos, tecendo signos e significados (DELEUZE, 1988).

Vivenciamos essa experiência com profundo prazer e alegria. A produção de memórias transformadas em escritas de si permitiu encontrar intercessores com as coisas, lugares, tempos, sensações, pessoas, experimentadas pela imaginação: "sentir o cheiro do campo, sentir o vento no rosto, exatamente como estou agora..."; "lembra quando ficávamos horas e horas no campo correndo os quero-queros?"; "dormir embaixo das árvores, sem medo, sentindo a brisa da natureza, dos banhos no rio..."; "os banhos de chuva, as brincadeiras na rua..."; "subir nas árvores, às vezes para comer os frutos, às vezes para contemplar a natureza...".

Aí percebemos uma marca cultural comum das infâncias na região em que vivemos e que, de certo modo, ainda é possível de ser experimentada pelas crianças daqui nos dias atuais: brincar em conexão com elementos da natureza vivos e não-vivos, terra, água, vento, pedras, plantas, animais, numa fluência e sinergia que remete a transfiguração de todas as formas e extravasa em devires criança:

No brincar, a imaginação quer todas as possibilidades de imaginar. A imagem pede mais imagem. E em cada um dos quatro elementos, as imagens, na brincadeira, criam narrativas diferentes, enredam o viver por aspectos diversos. A vida - social, material, cultural - ganha sempre a 
largura e a suspensão do ar, a fluência e a sinergia da água, a iluminura e a têmpera do fogo, a gravidade e o peso da terra. (PIORSKI, 2016, p. 117)

Brincar, um encontro com as infâncias a partir das escritas de si em que experimentamos devires criança, movimentos de criação de acontecimentos outros, desterritorialização das formas estabelecidas dos seres, tempos e espaços. Devir criança que se opõe a uma mera "lembrança de infância", pois a linha de desterritorialização que se experimenta avizinha-se da infância, sem tornar-se ela própria, ou seja, não é possível voltar a ser a criança que fomos, nem tão pouco, deixar de ser o adulto que somos. Mas, liberar-se desses pontos de origem e de chegada, movendo-se entre eles na precipitação de uma relação que os leva a desaparecer, pois: "o devir não se pensa em termos de passado e futuro", "ele passa entre os dois. Todo devir é um bloco de coexistência"(DELEUZE; GUATTARI, 2012b, p. 94).

Ao experimentar devir criança não somos nem crianças, nem adultos, atravessamos essas formas pré-existentes pelas quais se define os estágios de uma vida e de uma condição de existência infantil ou adulta. Devir é movimento perpendicular que acontece entre formas delimitadas, estratificadas, forjado em velocidade absoluta ao ativar potências de abertura, ao mesmo tempo, sobre o mundo, as coisas e nossas existências. Assim que, brincar é a arte de experimentar devires, fantasiar outras vidas, outros mundos além do que conhecemos. Sonhar sem limites.

\section{Dos sonhos que se sonha junto}

Para nós, o Curso de Extensão multiplicou forças, vontade de potência, tornou-se experiência, imprevisibilidade em invenções de existências no cuidado consigo mesmo e com outros/as. Ato ético, estético e político, experimentado em devaneios de infâncias imaginadas, que nos envolveu e moveu à criação de devires criança.

Daí a potencialidade desse deslocamento em tempos e espaços outros: "outras maneiras de constituir o êthos do sujeito. Esta é necessariamente uma ação compartilhada, que se dá em relação com os outros. $O$ modo artista docente pode surgir assim no entreespaço da escrita de si e das relações de amizade" (LOPONTE, 2005, p. 04).

A escrita de si por meio das cartas para as infâncias foi um encontro com infâncias imaginadas, criadas em devaneios, num momento de interrupção do tempo chrónos para a 
afetação do tempo aión. A abertura ao inusitado, ao diferente, produzida com as escritas de si, traz à cena a metáfora da navegação, descrita por Foucault (2004). Ora, tal metáfora faz relação com a noção de um deslocamento efetivo, real do sujeito consigo mesmo. Movimento em que "O sujeito deve ir em direção a alguma coisa que é ele próprio" (p. 302). Operação de "deslocamento, trajetória, esforço" (p. 302).

Tal discussão articula-se ao tema do retorno a si, que pode ser pensada como uma dobra, um movimento que o sujeito deve fazer funcionar sobre si. Se nesse "deslocamento efetivo de um ponto a outro" (p. 302) é exigida uma finalidade, um objetivo, com as cartas a meta era um encontro "com a infância do que somos e do que podemos ser", e isso, "na medida em que ela é experiência, é inerentemente transformadora do que somos, sem importar a idade" (KOHAN, 2005, p. 249).

Além disso, Foucault (2004) refere que nesse processo de deslocamento de si "o porto ao qual nos dirigimos é o porto inicial'(p. 303) e junto com os perigos de tal deslocamento, atingir tal porto "implica um saber, uma técnica, uma arte." (p. 303). A nosso ver, a partir das cartas para a infância a escrita de si acionou que cada professora efetivasse, consigo mesmo, uma trajetória ao encontro das intensidades de suas infâncias. Uma produtiva escolha de existência a fim de manter aberto o campo das possibilidades e o sentido de transformar a si.

Ao mesmo tempo: o que, afinal, somos capazes de pensar e criar a partir do encontro com a nossa infância atual e inatual? Deleuze (1992, p. 156) diz que:

O essencial são os intercessores. A criação são os intercessores. Sem eles não há obra. Podem ser pessoas - para um filósofo, artistas ou cientistas; para um cientista, filósofos ou artistas - mas também coisas, plantas, até animais, como em Castañeda. Fictícios ou reais, animados ou inanimados, é preciso fabricar seus próprios intercessores.

Evidências de um processo em que olhar para si reafirma a alteridade em relação com os outros. É recorrente o entendimento de que o outro é necessário para a nossa própria produção. Nesse caso, o outro como uma dobra de si, um fora com o qual cada um se perturba, se agita de um porto a outro de sua escrita navegante. Um deslocamento que implicou no entendimento de que "Essa forma da subjetividade, que chamamos de infância, não tem idade" (KOHAN, 2005, p. 249).

$\mathrm{E}$, pretendemos que essas experimentações continuem movimentando potências para a invenção de fazeres e docências na Educação Infantil com crianças pequenas. Múltiplas infâncias que são experimentadas pelas crianças que habitam as escolas, as ruas, os bairros das cidades. O que requer a abertura para diferentes modos de existir nas infâncias. 
Infâncias como multiplicidades de multiplicidades, pois, inspiradas em Deleuze e Guattari (2012a, p. 23) entendemos que “[...] é somente quando o múltiplo é efetivamente tratado como substantivo, multiplicidade, que ele não tem mais nenhuma relação com o uno como um sujeito ou como objeto [...]".

Tempos, lugares e relações que traduzem a arte da existência de um fazermo-nos docentes no mundo que habitamos. Tratando-se de "uma operação estreitamente vinculada ao trabalho da criação, que opera em processo de tradução permanente e, nesse sentido, como um exercício intensivo de pensamento" (AQUINO; CORAZZA; ADÓ, 2018, p. 10).

Trata-se de afirmar o pensamento que surge do exterior, ao passo que, ao olhar para nossos fazeres acionamos novas potências. Nesses momentos, assumimos a condição de um outro situado no presente que olha para as suas vivências passadas e as recria ao narrá-las. Assim como anuncia Gallo (2008, p. 09), inspirado na Filosofia da Diferença de Deleuze: "Um pensamento do exterior é um pensamento do outro. Mas não do outro como um 'outro eu', e sim do outro enquanto tal, do outro que está, inclusive, no eu. Afirmar o pensamento do exterior significa afirmar a diferença como diferença, sem um retorno ao mesmo".

Desse modo, cada existência se torna única, não apenas pela individualidade do ser, mas pelas formas como nos tornamos o que somos nas relações que estabelecemos conosco mesmo, com as coisas e com as outras pessoas com quem habitamos os lugares e tempos das nossas vidas assim como expressa a poesia Os Temperos dos Tempos da Infância, de Gustavo Tanus Martins (2018):

Ganhar tempo. Aproveitar tempo.

Perder tempo. Administrar o tempo.

Aproveitar o tempo. Perca tempo.

Perceba o tempo. Perceber o tempo.

Khrónos - quantidade

Kairós - oportunidade

Aión - experiência

Quanto tempo tenho? Quantidade.

Quanto tempo falta? Oportunidade.

Qual é o seu tempo? Experiência.

Ontem o tempo passou!

Hoje o tempo passa!

Amanhã o tempo passará!

Tudo é tempo.

Nada tem tempo.

Somos nosso tempo de vida e o tempo que nos resta à vida.

Vivemos ou "tempemos"?

Você vive a sua vida ou apenas deixa o tempo vive-la?

Você vive a sua vida ou perde tempo com a vida dos outros?

Tempo relativo... Futuro.

Tempo passageiro... Passado. 


\author{
Tempo presente! \\ Qual o tempo da infância? Aión. \\ Como a escola lida com o tempo? Khrónos. \\ Como são as crianças de cada tempo? Kairós. \\ Há um tempo filosófico que podemos pensar a filosofia da infância? \\ A infância preocupa-se com a filosofia? \\ E a filosofia pensa na infância? \\ Brinca e infância: "brincância" \\ Filosofia e infância: "filosofância" \\ Tempo e infância: "temperância" \\ A escola da infância: "escolância" \\ O tempo apressa momentos, pesa em excessos, represa possibilidades. \\ A infância, com leveza, desacelera e liberta.
}

Experimentar infâncias em movimentos com outros intercessores: animais, natureza, família, outras crianças, etc. Entrelaçamentos tecidos entre pessoas, ambientes, texturas, odores, animais, ideias e palavras, entre outros, evidenciando a potência dos encontros que nos ajudam a sonhar e produzir um novo mundo, outros modos de habitar a educação e nossa relação com a docência e a infância. Conjunto de operações éticas, estéticas e políticas.

E, se falamos em intercessores, no plural, é porque o singular não o exprime, uma vez que se trata, sempre, de intercessores para desalojar o pensamento do instituído. Em suma, encontros que potencializam a criação de devires a partir do incitamento a um pensamento que vagueia.

\title{
REFERENCIAS
}

AQUINO, J. G.; CORAZZA, S. M.; ADÓ, M. D. L.Por alguma poética na docência: a didática como criação. Educ. rev. [online], Belo Horizonte, vol. 34, EPUB: jan./2018. Disponível em: https://www.scielo.br/scielo.php?script=sci_arttext\&pid=S010246982018000 $100108 \& \operatorname{lng}=$ pt\&tlng=pt> Acesso em: 17 set. 2020.

BACHELARD, G. A poética do devaneio. Tradução de Antônio de Pádua Danesi. São Paulo: Martins Fontes, 1988.

DELEUZE, G. Diferença e repetição. Tradução de Luiz Orlandi e Roberto Machado. São Paulo: Graal, 1988.

Conversações. Tradução de Peter Pál Pelbart. São Paulo: Ed. 34, 1992.

DeleuZE, G.; GUATTARI, F. Mil Platôs: Capitalismo e esquizofrenia2. Vol. 01. Tradução de Ana Lúcia de Oliveira, Aurélio Guerra Neto e Célia Pinto Costa. São Paulo: Editora 34, 2012a. 
Mil Platôs: Capitalismo e esquizofrenia 2. Vol. 04. Tradução de Suely Rolnik. São

Paulo: Editora 34, 2012b.

DORNELLES, L. V. Sobre o devir-criança ou discursos sobre as infâncias. In: V Colóquio Internacional de Filosofia da Educação, 2010, Rio de Janeiro. Anais do V Colóquio Internacional de Filosofia da Educação, Universidade Estadual do Rio de Janeiro, 2010. Disponível em: https://www.ufrgs.br/gein/wp-content/uploads/2016/10/sobre-o-devircrian\%C 3\%A7a-ou-discursos-sobre-as-infancias.pdf>. Acesso em: 17 set. 2020.

FOUCAULT, M. As Palavras e as Coisas: Uma arqueologia das Ciências Humanas. Tradução de Salma Tannus Muchail. $8^{a}$ ed. São Paulo: Martins Fontes, 1999.

A Hermenêutica do Sujeito. Tradução de Márcio Alves da Fonseca e Salma Tannus Muchail. São Paulo: Martins Fontes, 2004.

GALLO, S. D. de O. Deleuze e a Educação. Belo Horizonte: Autêntica, 2008.

KOHAN, W. O. Da maioridade à minoridade: filosofia, experiência e afirmação da infância. In: KOHAN, W. O. Infância. Entre Educação e Filosofia. Belo Horizonte: Autêntica, 2005, p. 237-254.

LARROSA, J. Tremores: Escritos sobre experiência. Tradução de Cristina Antunes e João Wanderley Geraldi. Belo Horizonte: Autêntica Editora, 2017.

LOPONTE, L. G. Docência artista: arte, estética de si e subjetividades femininas. 2005. Tese (Doutorado em Educação). Faculdade de Educação, Universidade Federal do Rio Grande do Sul, UFRGS, Porto Alegre, 2005.

MARTINS, G. T. Kairós: valsar com a infância, na escola, através da experiência filosófica. Revista Teias, v. 19, n. 52, p. 137-149, jan./mar. 2018.

PIORSKI, G. Brinquedos do chão: a natureza, o imaginário e o brincar. São Paulo: Petrópolis, 2016.

\footnotetext{
${ }^{\text {i }}$ Doutora em Educação (2012) pela Universidade Federal de Pelotas. Professora Associada da Universidade Federal do Pampa (UNIPAMPA/Campus Bagé - RS). Líder do Grupo de Pesquisa Philos Sophias nas linhas de pesquisa Educação e Filosofias Contemporâneas, Educação e Diversidade Cultural.Brasil. E-mail: dulce.voss@gmail.com ORCID: http://orcid.org/0000-0002-0672-7273.

ii Doutora em Educação pela Universidade Federal do Rio Grande do Sul (UFRGS). Professora da Universidade Estadual do Rio Grande do Sul (UERGS). Coordenadora do Grupo de Pesquisa DESLOGOGIAS - Educação, Culturas e Pedagogias (UERGS/CNPq). Brasil. E-mail: vicamozzato@gmail.com ORCID: https://orcid.org/0000-0003-2617-0529.

${ }^{\text {iii }}$ Mestra em Ensino pelo Programa de Mestrado Acadêmico em Ensino (PPGMAE) pela Universidade Federal do Pampa - UNIPAMPA. Professora colaboradora voluntária no Curso de Licenciatura em Pedagogia na Universidade Estadual do Rio Grande do Sul (UERGS). Membro dos Grupos de Pesquisa Philos Sophias e DESLOGOGIAS. Brasil. E-mail: semiramis_mc@ hotmail.com ORCID: https://orcid.org/0000-0002-9902-6774.
} 